\title{
LA RELACION DE TRABAJO SUBORDINADO BAJO EL PRISMA QUE OFRECE LA FIGURA DEL TRABAJADOR EN EL ESCENARIO EUROPEO Y COMUNITARIO
}

1. L a emergencia y sistematización juridica del trabajo subordinado: la trasposición del principio de igualdad formal al plano de la relación de trabajo.- 2. L a elección por el ordenamiento juridico español del instrumento contractual como mecanismo de delimitación y asignación de tutelas.- 3. El papel del ordenamiento comunitario en la delimitación actual de la relación de trabajo: la adecuación del prototipo normativo a la asignación de tutelas laborales. - 4. La recomposición de la noción de trabajador a la luz de la evolución del Derecho Comunitario y del Derecho Comparado Europeo: la tutela del trabajo prestado a favor de otro.

1. La emergencia y sistematización jurídica del trabajo subordinado: la trasposición del principio de la igualdad formal al plano de la relación de trabajo

Puede parecer inútil centrarse una vez más en el debate en torno a la noción de trabajador, por cuanto mucho se ha dicho ya sobre este tema. Sin embargo, no puede cuestionarse que determinar quién es trabajador y quién no y quién está o no protegido por el Derecho del Trabajo continúa siendo hoy por hoy tanto para la doctrina como para la jurisprudencia, uno de los aspectos más controvertidos de la disciplina laboral. Prueba de ello es la sucesiva y constante aparición de opiniones que, otorgando un cariz extensivo o restrictivo al ámbito subjetivo del Derecho del Trabajo, oscilan desde la defensa de un retorno a la regulación civil de los contratos o a la potenciación de la autonomía de la voluntad en la calificación del vínculo que une a las partes hasta la recuperación del criterio de la debilidad contractual de uno de los sujetos de esta relación como criterio delimitador del ámbito subjetivo de esta rama del ordenamiento jurídico. ${ }^{2}$

Estamos en un momento en el que se está esgrimiendo la necesidad de alcanzar los mayores niveles de rentabilidad posibles y de contener los costes empresariales, lo que para no pocos comporta también cuestionar la conveniencia de mantener unas normas del trabajo que son más fruto del pasado que del presente ${ }^{3}$. Esto es, el argumento económico se está empleando para desmantelar

\footnotetext{
1.- Profesora Ayudante Doctor de la Universitat Pompeu Fabra de Barcelona (España).

2.- Al respecto vid. RODRÍGUEZ PIÑERO, M., La buida del Derecho del Trabajo, RR.LL, 1992-I, pág.91; RIVERO LAMAS, J. y GARCÍA BLASCO J., Transporte de cosas y mercancias y contrato de trabajo, RR.LL, 1987-II, pág. 530 a 532; RODRÍGUEZ PIÑERO ROYO, M., La presunción de existencia del contrato de trabajo, Col. Estudios de Derecho Laboral, $n^{\circ}$ 21, Civitas (Madrid), 1995, pág. 223; PEDRAZZOLI, M., Lavoro sans prbase e ordinamento dei lavori. Ipotesi sul lavoro autonomo, RIDL, no 3, 1998, pág. 49 a 103; OJEDA AVILÉS, A., Encuadramiento profesional y ámbito del Derecho del Trabajo, RR.LL, 1988-II, pág. 151; y CASAS BAAMONDE, Ma Ea , y VALDÉS DAL RÉ, F., Diversidad y precariedad en la contratación laboral en España, RR.LL, 1989-I, pág. 243.

3 .- ICHINO, P., Un solo diritto e un solo mercato per il lavoro subordinato e il lavoro autonomo, en AA.VV., I "destini" del lavoro. Autonomia e subordinażione nella società postfordista (Dir. F. Amato), Franco Angeli (Milano), 1998, pág. 79 y ss. Sobre las trasnformaciones de los sistemas productivos y su repercusión sobre el Derecho del Trabajo vid. en AA.VV., El empleador en el Derecho del Trabajo. XVI Jornadas Universitarias Andaluzas de Derecho del Trabajo y de Relaciones Laborales (Coord. M. Rodríguez. Piñero Royo), Col. Andaluza de Relaciones Laborales, Tecnos (Madrid), Vol.1, 1999: O'KEAN ALONSO J.M., El nuevo entorno económico dela empresa, pág.17 a 28; CRUZ VILLALÓN, J., Los cambios en la organización de la empresa y sus efectos en el Derecho del Trabajo: aspectos individuales, pág. 29 a 57; y
} 
Revilla - La relación de trabajo subordinado (...) en el escenario Europeo y Comunitario

sistemas de protección social de larga tradición y como excusa para ralentizar un desarrollo social que ya no puede ir a la par del desarrollo económico ${ }^{4}$. Afortunadamente, no todo es negativo en este panorama pues existe todavía un consenso implícito entre los gobiernos en torno a la existencia de normas laborales fundamentales, de suerte que lo que debe discutirse ya no es si éstas deben existir y ser respetadas, sino la forma en que deben hacerlo. ${ }^{5}$

La trayectoria de la regulación del trabajo en Europa ha sido dispar, oscilando desde su túmida regulación a mediados del siglo XIX hasta llegar a la actualidad, en la que el trabajo se ha convertido en el principal medio de integración social. Hoy más que nunca se asignan determinadas tutelas a ciertos ciudadanos en atención a su exclusiva participación en un mercado singular que es el de trabajo ${ }^{6}$. Esta circunstancia, que ahora se asume con práctica normalidad, es una conquista relativamente reciente que no es fruto del azar ni responde a una elección caprichosa del legislador sino que trae su causa de la constatación en un determinado momento de la desigual correlación de fuerzas existente en una relación de trabajo y la necesidad de crear un instrumento y un estatuto protector que corrija dicha desigualdad. Esta función socializadora que se asigna inicialmente y de forma vocacional al ordenamiento laboral hoy en día parece que se está invirtiendo ya que no son pocos los ejemplos que muestran como la individualización y precarización de la relación de trabajo, así como el desfase entre la regulación entre norma y realidad, están postergando a determinadas personas a un estado de exclusión social7.

Ni es éste un debate nuevo ni es tampoco un debate que se preste a soluciones fáciles o definitivas. Pero si fue esta rama del ordenamiento jurídico la que desde su nacimiento confirió al trabajo y al sujeto que lo presta valor y dignidad en Europa ${ }^{8}$, es a quien corresponde realizar la tarea de recomposición necesaria para convertir en realidad la igualdad material que se promulga en algunos textos constitucionales (ver en este sentido el art. 9.2 de la Constitución Española).

Como se ha dicho ya el reconocimiento legal de la actual noción legal de trabajador es el resultado de una evolución gradual que hunde sus raíces en los albores del sistema de producción

ARIZA MONTES J.A., y VELASCO PORTERO, T., La reingeniería de procesos y sus consecuencias sobre el contrato de trabajo, pág. 231 y ss.

4.- BAYLOS GRAU, A., Globalización y Derecho del trabajo: realidad y proyecto, CRL, no 15, 1999, pág. 19 a 49; APARICIO TOVAR, J., Los derechos sociales ante la internacionalización económica en AA.VV., La reforma del marco normativo del mercado de trabajo y el fomento de la contratación indefinida: puntos críticos (Coord. J.M. Monereo Pérea), Comares (Granda), 1999, pág. 17 y ss.; y SPYROPOULOS, G., Les relations professionelles dans le tourbillon de la modalistion, DS, $\mathrm{n}^{\circ} 3,1999$, pág. 230 y ss.

5.- CASAS BAAMONDE, $\mathrm{M}^{\mathrm{a}} \mathrm{E}^{\mathrm{a}}$, Las transformaciones del Derecho del Trabajo y el futuro del Derecho del Trabajo, en AA.VV., El trabajo ante el cambio de siglo: un tratamiento multidisciplinar. Aspectos laborales, fiscales, penales y procesales (Coord. M.R. Alarcón y Ma.M. Mirón), Marcial Pons (Madrid), 2000, pág. 201.

6.- ALARCÓN CARACUEL, M.R., La ajenidad en el mercado: un criterio definitorio del contrato de trabajo, REDT, $\mathrm{n}^{\circ}$ $28,1986$.

7.- ROJO TORRECILLA, E., El reto de lo social en la nueva Europa del tercer milenio, Revista de Fomento Social, vol. 15, n 218, pág. 161 y ss; y RODRÍGUEZ PIÑERO, M., Empleo y exclusión social, RR.LL, n 10, 2002, pág. 2 y ss.

8.- VENEZIANI, B., La evolución del contrato de trabajo, en AA.VV., La formación del Derecho del Trabajo en Europa. Análisis comparado de la evolución de nueve países hasta el año 1945. Col. Informes, Madrid (MTSS), 1994. Para una visión sobre el vínculo existente el trabajo y la ciudadanía social vid. ACCORNERO A., Il lavoro come diritto $e$ come cittadinanza, Lav. Dir., n 4, 1996, pág. 729 a 732; FERRAJOL, L., Derechos y garnatías. La ley del más débil, Trotta (Madrid), 1999, pág. 98 y 99; y GAETA, L., Derecho del Trabajo y alteridad, figuras de la fiversidad modelos culturales, en AA.VV., Nuevos escenarios para el Derecho del Trabajo: familia, inmigración y noción de trabajador. Homenaje a Mássimo D’Antona (Coord. J. López López), Marcial Pons (Madrid), 2001, pág. 218. 
REJ - Revista de Estudios de la Justicia - No 5 - Año 2004

capitalista. Esta constatación que parece simple, permite extraer dos consecuencias que conviene tener en cuenta en el debate actual sobre la función tutelar del ordenamiento laboral.

Por un lado, que aun que el trabajo humano como hecho social existe desde tiempos inmemoriales su delimitación normativa no se ha producido hasta hace relativamente poco tiempo. Esta situación ha provocado que el término "trabajo-trabajador" responda a múltiples situaciones unas sociales y otras, por así decirlo, "normativas", que no son siempre coincidentes necesariamente. Así, mientras hay usos del término que se pierden en el tiempo hay otros que son más recientes y están íntimamente ligados a un sistema determinado de organización social.?

Lo que hoy conocemos y llamamos "trabajo y trabajador" es una invención de la modernidad; la forma en que los conocemos, lo practicamos y los situamos en el centro de la vida individual y social fue inventada y luego generalizada con el industrialismo ${ }^{10}$. De tal modo que, mientras la colectividad otorga un significado al término "trabajo-trabajador" íntimamente ligado al momento histórico en el que está, el legislador vincula esa delimitación al sistema de producción al que pertenece, por una noción tributaria del momento histórico en el que nace, y cambiante porque no sólo evoluciona paralelamente a la sociedad que la vio nacer sino porque su contenido varía en función de los cambios que la sociedad experimenta. Es una noción histórica y dinámica al mismo tiempo.

Si es cierto que el término "trabajo" goza de diferentes sentidos, por un lado, el que la sociedad le atribuye -supuestamente constatando la propia realidad que vive-, y por otro, el que el legislador considera adecuado; no dejamos de estar ante una noción que está haciendo referencia a realidades diversas, una social y otra jurídica. Trasladando esta reflexión a nuestro debate ello supone que en algún momento, situado en los inicios del sistema de protección capitalista, el legislador opta por atribuir al término "trabajo-trabajador" un alcance distinto del que la sociedad en ese momento le atribuye. Esta decisión es importante por dos motivos: por un lado, porque marca el instante en que ciertas manifestaciones del término "trabajo" van y no van a tener relevancia jurídica -pese a que estas últimas puedan conservar su sentido a nivel social- y por otro lado, porque dicha elección va a condicionar toda la actuación posterior del legislador. Por lo que cualquier análisis y crítica a la actuación legislativa deberá forzosamente hacerse bajo esta clave.

Por otro lado, el principio que orienta la actuación legislativa ni es arbitrario ni aleatorio, se justifica en la constatación de una realidad concreta que se produce como consecuencia directa de la transición de un sistema de organización económica no industrial a otro predominantemente industrial y las consecuencias que ello tiene sobre el determinados segmentos de la sociedad, en lo que se ha venido a denominar la "cuestión social"11. La apreciación por el legislador de un desigual juego de fuerzas entre los sujetos que intervienen en determinadas relaciones de trabajo le lleva a crear un tipo

9.- RIFKIN, J., El fin del trabajo, Col. Estado y Sociedad, Barcelona (Paidós), 1996, pág. 23; SANTOS ORTEGA, A., y POVEDA ROSA, M., Trabajo, empleo y cambio social, Valencia (Tirant lo Blanch), 2001, pág. 22 a 27. Sobre el valor asociado al trabajo y sus transformaciones vid. en AA.VV, Le travial en perspectives (Dir. A. Supiot), LGDJ (Paris), 1998: CASTEL, R., Travail et utilité au monde, pág. 15 a 22; y MÉDA, D., Une mise en perspective de la valeur travail, pág. 32 a 44.

10.- Para tener una perspectiva de los distintos sentidos que se otorga al término trabajo vid. GORZ, A., Metamorfosis del trabajo, Madrid (Sistema), 1995, pág. 25.

11.- HEPPLE, B., Introducción, en AA.VV., La formación del Derecho del Trabajo en Europa. Análisis comparado de la evolución de nueve paises hasta el año 1945 , Co. Informes y Estudios, MTSS (Madrid), 1994; ALONSO OLEA, M., La revolución industrial y la emergencia del Derecho del Trabajo, RT, nº 32, pág. 43 y ss; y PALOMEQUE LÓPEZ, C., Derecho del Trabajo e Ideología, Civitas (Madrid), 1995, pág. 30 y ss. 
Revilla - La relación de trabajo subordinado (...) en el escenario Europeo y Comunitario

de contrato en el que pese a que intervengan dos sujetos, uno de ellos será prácticamente su protagonista. La aparición del contrato de trabajo como instrumento que visualiza la desigual posición de las partes de la relación de trabajo supone en realidad llevar el principio de igualdad formal que comporta un contrato a una situación de desigualdad sustancial que se da entre las partes de una relación de trabajo ${ }^{12}$.

El paso siguiente es constatar cuándo se da esa situación de desigualdad sustancial que fuerza al legislador a intervenir en una relación entre privados. Es decir, constatada la desigualdad material entre las partes de un contrato de trabajo -premisa que puede parecer contradictoria con la naturaleza intrínseca de un contrato dado que las partes se presuponen iguales- el ordenamiento jurídico actúa compensando dicha desigualdad por medio del establecimiento de unas tutelas singulares de las que sólo gozarán determinados sujetos. Existe pues una correlación directa entre los sujetos a quien el ordenamiento jurídico otorga su tutela y el criterio que justifica la intervención legislativa en una relación jurídica privada. El legislador pretende lograr un equilibrio entre la igualdad formal que conlleva el contrato de trabajo y la igualdad material que comporta la exclusiva tutela de una de las partes de dicho contrato.

Sin embargo, hay que tener en cuenta que la intervención legislativa esta condicionada por el momento y las circunstancias en que se produce. El Derecho refleja normas y valores estrechamente ligados a la historia y a la cultura de las sociedades que regula. Lo que significa que en el análisis sobre la noción de trabajo-trabajador también hay que tener en cuenta las principales tradiciones culturales que en su día alimentaron su conceptuación jurídica. En Europa básicamente son dos: la procedente del Derecho Romano y la procedente del antiguo Derecho Germánico.

La tradición romanista, que no es otra que la que recogen los derechos europeos del siglo XIX, conceptúa la relación de trabajo como una operación de intercambio entre sujetos formalmente iguales, esto es, sitúa a la relación de trabajo en la órbita del Derecho de obligaciones en perfecta sintonía con el pensamiento económico liberal, que se construye a partir del siglo XVII y que crea la idea de mercado sobre la base del principio del libre intercambio entre individuos formalmente iguales. Por su parte la tradición que proviene del antiguo Derecho germánico conceptúa a la relación de trabajo como una situación de pertenencia personal a una comunidad, es decir, sitúa a la relación en la órbita de un status personal. Al contrario que la visión contractualista, que hace prevalecer la relación de los hombres con las cosas para hace posible el intercambio de trabajo, conceptuado como un objeto, a cambio de un salario, la tradición germanista restituye al primer lugar del análisis la relación entre personas, tal y como se hacía en el análisis jurídico preindustrial. La influencia de ambas culturas o corrientes de pensamiento es visible hoy en día tanto en los ordenamientos jurídicos del entorno europeo como en el mismo Derecho Comunitario. De forma que la noción de contrato de trabajo o de relación de trabajo es en numerosos países de la Unión Europea el resultado de una combinación de culturas jurídicas o lo que es lo mismo de una combinación de intercambio y de relación personal. Combinación que se produce de modo y en proporción diferente, lo que provoca la existencia de diferencias jurídicas en los modelos sobre la relación de trabajo en los distintos países del entorno europeo.

12.- BAYLOS GRAU, A., Derecho del Trabajo: Modelo para armar, Madrid (Trotta), 1991, pág. 20. 


\section{La elección por el ordenamiento jurídico español del instrumento contractual como mecanismo de delimitación y asignación de tutelas}

Aunque sea cierto que en todos los países de la Europa comunitaria es el contrato el que ha servido como marco para la definición jurídica de la relación de trabajo, sin embargo esta exclusividad ha sido posible al precio de absorber un estatuto específico, que se encuentra definido en escalones diversos por la ley, el convenio colectivo, la jurisprudencia o la costumbre.

La emergencia de la noción de trabajo en abstracto, esto es desligada de cualquier referencia a una profesión determinada o a una regulación igualmente determinada propia de concepciones preindustriales del trabajo, y del esfuerzo de su sistematización jurídica, desemboca como se ha visto en la consagración del contrato de trabajo. Este contrato no sólo va a ser el objeto de tal o cual disposición del ordenamiento jurídico sino que al mismo tiempo va ser el criterio discriminador del campo de aplicación de una determinada rama del ordenamiento jurídico, la laboral: es la llave que abre la puerta del edificio jurídico de las tutelas laborales. Sin embargo, el esfuerzo de sistematización jurídica no se ha llevado a cabo de igual forma ni al mismo ritmo en todos los países europeos. Mientras que en unos países se ha apostado por entender que el contrato de trabajo es un concepto al mismo tiempo unificado y aglutinador; en otros se ha visto el contrato como una realidad diversa y difícilmente aprehensible. Mientras que la primera visión, (propia de países como Portugal, Italia, España, Países Bajos, Francia, Luxemburgo, Bélgica o Alemania) más "sistemática” si se quiere, supone que la definición uniforme del contrato de trabajo, y la de trabajador que se desprende, ejercen un importante poder de atracción sobre formas concretas de organizar el trabajo; la segunda, por el contrario, más "casuística" y propia de países en los que el convenio colectivo ha desempeñado un papel importante como Gran Bretaña, Irlanda o Dinamarca, conlleva la ausencia de unos contornos firmes que impiden que el contrato juegue ese papel de referencia común.

Estar ante una u otra aproximación es relevante dado que cada una de ellas tiene una incidencia extremadamente diferente en la concepción del Derecho del Trabajo en su conjunto. Una visión más casuística hace innecesaria una definición del contrato de trabajo que tenga alcance general, puesto que basta que se concrete caso por caso cuando sea necesario. Es decir, cada disposición legal define su propio campo de aplicación a través de la definición propia de los contratos o de las personas que quedan sujetos a ella. Por el contrario una aproximación sistemática obliga al establecimiento de una definición legal o jurisprudencial única del contrato de trabajo, al ser éste el elemento que sirve para circunscribir el campo de aplicación del Derecho del Trabajo. Mientras la primera opción refleja el interés sobre la diversidad de estatutos aplicables a los trabajadores; la segunda opción, por el contrario, aglutina a todos los trabajadores alrededor de un solo estatuto.

El caso español es ejemplar desde una perspectiva sistemática porque en él la definición del contrato de trabajo coincide con el campo de aplicación del Derecho del Trabajo, de forma que la definición de esté último determina automáticamente la definición de aquél. Así, para delimitar la noción española de trabajador hay que tener en cuenta, en primer lugar, el art. 1.1 del Estatuto de los Trabajadores ${ }^{13}$ que establece que dicho cuerpo normativo se aplica a quien "voluntariamente preste sus servicios retribuidos por cuenta ajena y dentro del ámbito de organización y dirección de otra persona". De esta caracterización escueta de la prestación laboral de la que nada más dice el texto normativo pueden extraerse las siguientes conclusiones.

13.- Para un análisis en profundidad de este artículo y sus antecedentes, así como del ámbito subjetivo del Derecho del Trabajo español puede consultarse: REVILLA ESTEVE, E., Noción de Trabajador y Ordenamiento Jurídico, Tesis Doctoral, Universitat Pompeu Fabra (Barcelona), 2001. 
En primer lugar, y quizás la más obvia pero no por ello menos importante, el legislador no define expresamente o de manera directa al trabajador sino que, en su lugar, opta por caracterizar su prestación de servicios del que será trabajador. La condición de trabajador se deduce como resultado de ser parte de una relación entre dos sujetos, siendo ésta precisamente la que sí se caracteriza. Esto supone que la noción de trabajador está íntimamente conectada con el objeto de dicha relación, es decir, la prestación de servicios. Si esto es así existe una conexión clara a nivel del ordenamiento jurídico laboral entre trabajador como parte de un contrato de trabajo y el sujeto a quien dicho ordenamiento otorga protección.

En segundo lugar, y como consecuencia de lo anterior, no todo sujeto que preste sus servicios a otra persona goza de la protección que dispensa el ET, sino que sólo se tutela a aquel cuya prestación de servicios reúne las notas que el mismo texto normativo enumera. Produciéndose en este punto una fractura entre el prototipo normativo que contempla el art.1.1 ET y la realidad social básica que pretende regular.

Y en tercer lugar, la conceptuación jurídica de la noción de trabajador no acaba en el proceso deductivo derivado del art. 1.1 ET. La noción jurídica de trabajador no se reduce a constatar la concurrencia o no en la misma de los presupuestos sustantivos enumerados por el artículo estatuario, sino que además requiere de la intervención legislativa y de la interpretación jurisprudencial en determinados supuestos frontera en los que la presencia de aquellos sea controvertida.

Por otro lado, el apartado $1^{\circ}$ del art.1 ET no es el único que sistematiza la noción de trabajador en el ordenamiento jurídico español, dado que también es necesario acudir al juego combinado del mismo con el apartado $3^{\circ}$ del mismo artículo, que hace referencia a las relaciones de trabajo excluidas, y a la Disposición Final Primera, que establece que el trabajo por cuenta propia no estará sometido a la legislación laboral. Por consiguiente, junto al importante papel que desempeña el art.1.1 ET en la delimitación de la noción legal de trabajador existen otra serie de preceptos que coadyuvan a trazar el cuadro subjetivo sobre el que se proyecta la legislación laboral española y sobre la que en definitiva el legislador español ha decidido erigir la noción jurídica de trabajador.

Igualmente, no cabe olvidar el importante papel que desempeñan los arts. 2 y 8.1 ET en la delimitación del cuadro subjetivo de referencia del Derecho del Trabajo español. Mientras que el primero consagra las denominadas relaciones laborales especiales, el segundo contempla la "presunción de laboralidad", cuyo juego resulta especialmente útil con respecto a la calificación de aquellas relaciones de trabajo situadas en las denominadas "zonas grises" del Derecho del Trabajo. El reconocimiento legal de la existencia de unas relaciones laborales especiales, supone aceptar la pluralidad y diversificación de la noción legal de trabajador, al igual que sucede en la realidad. Implica cuestionarse la existencia de una única frontera normativa entre las relaciones que contempla y las que excluye, implica apostar por la diversificación normativa al conllevar la fragmentación del tipo normativo contenido el art.1.1 ET. El prototipo normativo del trabajo subordinado por cuenta ajena que aquél contempla deja de ser un espacio homogéneo o uniforme. Naturalmente esta regulación asimétrica comporta un aumento de la incertidumbre en la calificación como laborales de determinadas relaciones de trabajo, que se sitúan así en las "zonas grises". Incertidumbre que no deja de acrecentarse si a este escenario se le añade además, por un lado, la opinión de que no tiene porque existir un único prototipo normativo-social de referencia que justifique la intervención del Derecho del Trabajo; y, por otro, el que se cuestione la adecuación de la noción legal a la función tutelar del débil propia de un sistema socioeconómico determinado que en los últimos tiempos ha cambiado enormemente como resultado de los avances tecnológicos.

Sin duda alguna, uno de los problemas a los que más directamente se está enfrentando el 
ordenamiento jurídico laboral deriva del desfase entre el prototipo normativo y su realidad social subyacente. Este desajuste entre el reconocimiento legal y su función tuitiva esta comportando la desprotección de colectivos que pese a no ser considerados jurídicamente como trabajadores comparten con estos su misma situación de desigualdad material. Este desafio ha sido abordado a nivel doctrinal de diversas maneras. Por un lado, hay quien ha optado por interrogarse una vez más por las fronteras del trabajo asalariado, es decir, quienes han de ser tutelados y quienes no en su trabajo. Las posiciones han sido variadas y se extienden desde los que apuestan por una repliegue de la normativa laboral que permita que el Derecho Civil o el Derecho mercantil recuperen ciertas parcelas que en su día absorbió el Derecho del Trabajo, hasta los que consideran que la noción de trabajador debiera ampliarse abarcando incluso ciertas parcelas de trabajo autónomo. En este sentido han sido notables los intentos de algunos ordenamientos comparados, especialmente destacables en el caso italiano, por proteger de forma distinta, a como se tutela el trabajo asalariado, a ciertas parcelas de trabajo autónomo que al prestarse bajo formas de organización coordinada resultan próximas al trabajo subordinado.

Precisamente la constatación de estas necesidades de tutela de colectivos actualmente excluidos de la normativa laboral ha conducido a replantearse la función misma de tutela que secularmente se ha venido reconociendo desde su nacimiento al Derecho del Trabajo. La discusión gira ahora sobre el fundamento que justifica la intervención y tutela del ordenamiento laboral, y no sobre el tipo de sujetos a los que tiene que ir dirigida. Se cuestiona el fundamento mismo de la disciplina al interrogarse sobre su capacidad para seguir tutelando al sujeto débil de la relación de trabajo.

Para salvar este inconveniente, y recuperar así la función de protección del débil, es necesario reformular la noción de "trabajo" y consecuentemente la noción de "relación de trabajo" que se deriva. De forma que se proteja no sólo al trabajador que tenga una relación de trabajo gracias a un contrato de trabajo -tipo contractual que aun siendo el central no debe ser el único que abra la puerta de la tutela laboral- sino que también se tutele a quien preste un trabajo a otro por medio de un vínculo jurídico cualquiera que sea su naturaleza. Como tendremos ocasión de apreciar más adelante, este planteamiento resulta plenamente coincidente con el que se está dando en el plano comunitario y con el que también parece estar consolidándose en los ordenamientos de nuestro entorno ${ }^{14}$.

Sin duda alguna, la apuesta por una formulación tan abierta puede tener el inconveniente para algunos que no resuelve por completo los desafíos que se le plantean en la actualidad al Derecho del Trabajo. Sin embargo, constituye un punto de partida que permite que el Derecho del Trabajo recupere su función de protección del débil sin que por ello tenga que renunciar a las conquistas arduamente conseguidas y a los fundamentos que en su día justificaron su nacimiento.

En una época en la que se propugna el desmantelamiento de ciertos estándares sociales es conveniente apuntar que el avance en lo económico no está reñido con el mantenimiento de los valores sociales que consagran los ordenamientos jurídicos europeos. Por este motivo no sólo debe mantenerse una noción de trabajador que se derive de su condición de parte del contrato de trabajo sino que también debe ampliarse a todos aquellos sujetos que materialmente se encuentren en su misma situación de necesidad de protección. Debe asumirse que el criterio que debe guiar la reformulación de la noción legal de trabajador ha de estar en directa correspondencia con la función

14.- Para una visión sobre los primeros pasos de esta tendencia en el ordenamiento jurídico español vid. OJEDA AVILÉS, A., La saturación del fundamento contractualista. La respuesta autopoyética a la crisis del Derecho del Trabajo, REDT, nº 111, 2002, pág. 333 a 344. 
Revilla - La relación de trabajo subordinado (...) en el escenario Europeo y Comunitario

que desde sus orígenes ha desempeñado el ordenamiento jurídico laboral: poner límites a la desigual correlación de fuerzas existente en la relación de trabajo. ${ }^{15}$

\section{El papel del ordenamiento comunitario en la delimitación actual de la relación de trabajo: la adecuación del prototipo normativo a la asignación de tutelas laborales}

En las páginas precedentes se ha mencionado que cualquier regulación jurídica es un reflejo de normas y valores que se encuentran estrechamente ligados a la historia y a la cultura de las sociedades que regula. En este sentido se ha visto como la historia de las sistematización jurídica de la relación de trabajo en Europa está íntimamente ligada a dos tradiciones culturales o líneas de pensamiento: la romanista y la germánica. Sin embargo, el Derecho Comunitario no comparte esta situación; porque ni su proceso de conformación es fruto de un largo proceso evolutivo ni sobretodo, está incardinado en una cultura nacional determinada dado que su objetivo es sobreponerse a la diversidad de las culturas nacionales europeas.

Además en este punto, resulta también de máxima importancia retener que el fundamento de la intervención normativa de la Unión Europea en el ámbito social, a diferencia de los objetivos que persigue la intervención normativa de los Estados miembros, no es atemperar o conciliar el conflicto latente en la relación de trabajo. El Derecho Social Comunitario tiene como objetivo principal la creación de un mercado europeo fundamentado en la libre competencia, en el que se producen una serie de intercambios entre los Estados que lo integran. En este contexto el trabajo como hecho social también se ve involucrado, de ahí que sea objeto de regulación pero sólo en la medida en que constituye un intercambio económico, y por consiguiente parte del desarrollo de dicho mercado. Dicho de otro modo la relación de quien vende su fuerza de trabajo a un ajeno es percibida en sí, como un hecho económico, sin descender a la situación de desigualdad negocial que es motivo de tutela. Este planteamiento economicista de la relación de trabajo explica, sin duda, que las primeras disposiciones comunitarias promulgadas en materia social raramente regulen la relación de trabajo en sí misma o se refieran al trabajador como sujeto integrante de relación alguna, y que, por el contrario, prime el tratamiento jurídico del trabajo en el marco de la libre circulación de trabajadores. Hay que señalar también que esta escasa voluntad inicial de la Comunidad de promover una regulación específica de la relación de trabajo en el marco del derecho individual es correlativa a la escasa voluntad de los Estados miembros que la componen de ceder su soberanía normativa en este terreno, y cuya justificación cabría encontrar en la existencia de importantes y diferentes tradiciones jurídicas y las implicaciones económicas de la materia social. De ahí que si se analiza el Tratado de Roma o el Derecho derivado pueda advertirse como las nociones de "trabajador asalariado", de "contrato de trabajo" o de "relación de trabajo", sean empleadas pero nunca definidas. ${ }^{16}$

\footnotetext{
15.- GONZÁLEZ ORTEGA, S., Cuestiones actuales (y no tanto) del Derecho del Trabajo, TL, ño 64, pág. 9 a 34.

16.- El Tratado de Roma alude a los "trabajadores" cuando menciona los objetivos del Fondo Social Europeo (art. 3 TCEE); la libre circulación de "trabajadores" (art. 48 y ss. TCEE); la Seguridad social de los "trabajdores" migrantes (art. 51 TCEE); la Seguridad e Higiene en el "trabajo" (art. 118 A TCEE); la igualdad de remuneración entre los sexos (art. 119 TCEE); los "trabajadores asalariados" en relación a la regla de la unanimidad (art. 100 A TCEE); la "mano de obra" en relación a los objetivos de la política social (art. 117 TCEE); "las actividades no asalariadas" en relación con el derecho de establecimiento (art. 52 TCEE); los "servicios" cuando menciona el derecho a su libre circulación (art. 60 TCEE). Las mismas expresiones se encuentran en el Derecho derivado, que utiliza también la noción de "actividad asalariada" en el art.1 del Reglamento 1612/68/CEE, 15 de octubre; de "actividad profesional" cuando hace referencia al acceso al empleo en el art. 2 de la Directiva 76/207/CEE, 9 de febrero; de "persona empleada por el empresario" en el
} 
Por otro lado, el empleo de esta terminología refleja también el propósito del legislador comunitario de situar el acento de su normativa en la persona del trabajador, y no en el tipo de vínculo jurídico que mantiene con su empleador, tomándolo en consideración en cuanto mero prestador de servicios, como una agente económico, dentro de un mercado. Desde esta perspectiva esencialmente económica, se comprende el interés de la Comunidad por desarrollar una normativa completa sobre la libertad de circulación que garantice el principio de igualdad de trato entre los trabajadores de los distintos Estados que decidan hacer uso de la misma, y de los derechos de seguridad social que obtengan en sus itinerarios profesionales, por cuanto su aseguramiento contribuye a la construcción del mercado libre que proclaman los tratados fundacionales comunitarios.

Lo cierto es que si como se ha visto en un principio, normar en pro de la construcción de un mercado único europeo constituye la única preocupación de la Comunidad, ésta paulatinamente adquiere conciencia de la necesidad de incorporar las cuestiones sociales entre sus políticas, de ahí que la "concepción profesional" del trabajador se extienda a otros textos normativos (como, por ejemplo, la Carta Comunitaria de los Derechos Sociales Fundamentales de los Trabajadores), dando así inicio a una tendencia progresiva a identificar en mayor medida al trabajador como sujeto, y como sujeto ligado a una profesión, sustituyendo progresivamente la concepción del mismo como mero sujetoparte de un intercambio económico. Por ello, según indica la jurisprudencia comunitaria la noción de trabajador "debe ser definida conforme a criterios objetivos que caractericen la relación de trabajo, teniendo en cuenta los derechos y deberes de las personas involucradas y que la característica esencial de la relación de trabajo es la circunstancia de que una persona preste, durante un cierto periodo de tiempo, a favor de otra o bajo su dirección, ciertos semicios y que en contrapartida reciba una remuneración'17

Esta preferencia por la trayectoria profesional del trabajador -en lugar de por el tipo contractual que lo une a la otra parte- no debe llevar a la conclusión de que el vínculo jurídico que une a las partes de una relación de trabajo carece de trascendencia alguna a escala comunitaria. Ello no es así porque supondría desconocer las tradiciones jurídicas imperantes entre los diferentes Estados miembros, en la medida que en la mayoría de ellos, como se ha indicado, el contrato de trabajo constituye la figura jurídica central sobre la que se construye el entero Derecho del Trabajo. Sin embargo, la propia diversidad que existe entre los Estados miembros en la forma de conceptuar jurídicamente la relación de trabajo conlleva de por sí el hecho de que la noción que la Comunidad emplee en el marco de sus competencias no pueda ser más que la combinación (o, en su caso, la abstracción) de todas ellas.

La normativa comunitaria presume que la noción de trabajador se extrae de su condición de sujeto parte de un contrato de trabajo y del estatuto que se adquiere cuando se trabaja para otro en ciertas condiciones. Sujeto parte de un contrato que definen los Estados conforme a sus respectivas tradiciones y beneficiario de un estatuto que la normativa y la jurisprudencia nacional y comunitaria se encargan de ir estableciendo a medida que se detectan las necesidades de tutela. Puede decirse entonces que la noción de trabajador que se emplea a nivel comunitario es de corte casuístico, examinadas las necesidades de tutela detectadas en el análisis de la realidad social se aprueba y promulga la normativa necesaria.

Por consiguiente, el problema de la definición de la noción de trabajador es abordada de

art. 3 de la Directiva 89/391/CEE, 12 de junio; o en el art. 1 de la Directiva 91/53/CEE, 14 de octubre, en relación a la obligación del empresario de informar al trabajador sobre las condiciones aplicables al "contrato de trabajo" o la "relación de trabajo".

17.- Asunto Levin o Asunto 53/81, Sentencia de 23 de marzo de 1982, Rep. 1982-III, pág. 1035 y ss. 
forma diferente de un texto normativo a otro. En un primer grupo de casos, el cuidado por definir las nociones de "trabajador", "relación de trabajo" o "contrato de trabajo" es expresamente abandonado por el texto comunitario o por la jurisprudencia a favor de los derechos nacionales (así sucede, por ejemplo en el caso de las Directivas sobre transmisión o cesión de empresa, insolvencia del empresario o sobre la información de las condiciones del contrato o de la relación de trabajo). En un segundo grupo de casos, la jurisprudencia ha impuesto o proporcionado una definición comunitaria, por ejemplo en el caso de las normas de puesta en funcionamiento del principio de libertad de circulación de trabajadores y en materia de protección de la salud y de las seguridad de los asalariados con empleo temporal o de duración determinada. Y finalmente en un tercer grupo de casos, la cuestión de la delimitación de la noción de trabajador o de contrato o relación de trabajo no parece haber sido planteada ni en los textos normativos ni por la jurisprudencia relativa a su aplicación (como es el caso, por ejemplo del principio de igualdad de sexos, principalmente en lo referente a la igualdad de trato, lógicamente porque su campo de aplicación desborda el mero marco del trabajo sea este el tipo que sea; o el caso de la Directiva sobre Despidos Colectivos) como también ocurre con las nociones de "vida" o "actividad profesional" que por el momento tampoco han planteado ningún problema de conceptuación.

No hay duda de que el Derecho Comunitario se ubica entre aquellos Derechos en los que la aproximación casuística ha conducido a un débil grado de sistematización jurídica de la noción de trabajador ya que bajo esta perspectiva, ciertamente no se hace necesario la existencia de una noción unificada de trabajador en la media en que cada norma se encarga de precisar su propio alcance. Lo que ha provocado que el sentido de estos términos sea por lo general variable e impreciso ${ }^{18}$. Sin embargo, esta tenue sistematización jurídica ha sido contrarrestada con la aproximación sumamente sistemática que ha efectuado la jurisprudencia comunitaria especialmente importante en el terreno de la libre circulación. Ello se explica en la intención del TJCE de imponer una definición unitaria de la noción de trabajador por la razón de que si su delimitación quedaba en manos de los derechos internos, cada Estado tendría entonces la posibilidad de vaciar el contenido del Tratado, al poder eliminar a voluntad la protección comunitaria de determinadas categorías de personas. ${ }^{19}$

Bajo el prisma de la libertad de circulación el término "trabajador" que se emplea en los Tratados fundacionales pretende englobar a todo nacional de cualquier Estado miembro que desempeñe un empleo remunerado en otro Estado miembro, en cualquier sector de la producción, los servicios y el intercambio (art. 48.2 TCEE, actual art. 39 TCE). Parecería entonces que son los Estados miembros quienes por medio de su legislación determinen qué sujetos son los que tiene un empleo remunerado a los efectos de la libre circulación comunitaria; sin embargo, esta impresión deja de ser cierta si se tiene en cuenta la jurisprudencia del TJCE. Pese a que el Tribunal reconozca que "los términos de trabajador y actividad asalariada no se encuentran expresamente definidos" en ninguna disposición comunitaria, para descubrir su significado hay que "recurrir a los principios de interpretación generalmente reconocido partiendo del sentido ordinario a atribuir a los términos en su contexto y a la lur de los objetivos del Tratado"20. Lo que significa que la libre circulación de trabajadores tiene claramente "un contenido comunitario"21 que es precisado por el legislador comunitario y por la interpretación que en cada momento pueda hacer de la misma el TJCE a resultas de su aplicación.

\footnotetext{
18.- MOREAU, M.A., Brèves observations dans una perspective commmunautaire, DS, nº 5, 1999, pág. 454.

19.- Asunto Unger o Asunto 75/63, Senetencia de 19 de marzo de 1964, Rep. 1964, pág. 347 y ss.

${ }^{20}$.- Asunto 53/81, op. cit.

21.- Asunto 75/63, op. cit.
} 
Para el Tribunal "Ias nociones de trabajador y de actividad asalariada definen el ámbito de aplicación de una de las libertades fundamentales garantizadas por el Tratado, y por ello no pueden ser interpretadas restrictivamente"22. Esta concepción amplia de la libertad de circulación, en la que como telón de fondo discurre el hacer prevalecer la lógica del mercado de trabajo por encima de otros factores como puedan ser la nacionalidad, vínculo contractual, etc., ha comportado que la noción de trabajador en ocasiones vaya más allá de los periodos de trabajo efectivo para englobar períodos de formación profesional o de búsqueda de empleo; llegando incluso a concebir como trabajador a aquel sujeto que "habiendo abandonado su empleo, es susceptible de conseguir otro". Lo que supone concebir como trabajador a cualquier sujeto que no siendo trabajador puede ser susceptible de adquirir nuevamente dicha calidad ${ }^{23}$.

Para el Tribunal la característica esencial de la relación de trabajo, o lo que es lo mismo sus criterios objetivos, es que "una persona cumpla durante un cierto tiempo, a favor de la otra y bajo la dirección de esta, prestaciones a cambio de algún tipo de remuneración" 24 . Por consiguiente tres son los criterios que permiten delimitar el tipo de trabajo que el TJCE engloba bajo el principio de la libre circulación de trabajadores: la ejecución de una prestación a favor de un beneficiario; el control de la forma de cumplimiento por parte del beneficiario; $y$, finalmente el carácter oneroso de la prestación.

La libre circulación de trabajadores afecta a "actividades reales y efectivas" y aquellas personas que "ejerzan o deseen ejercer una actividad económica"25, quedando excluidas únicamente "aquellas actividades tan reducidas que aparezcan como puramente manginales o accesorias" 26 . Debiéndose interpretar todos esto términos "según los criterios objetivos que caracterizan la relación de trabajo, en consideración a los derechos y deberes de las personas afectadas" 27 . Lo que lógicamente comporta que las partes de la relación de trabajo no tengan algún tipo de poder sobre la calificación jurídica de su relación.

El que se trate de una actividad económica ha sido reiteradamente exigido por la jurisprudencia del TJCE desde el Asunto Unger. La exigencia de este requisito ha comportado una enorme casuística que ha permitido al Tribunal pronunciarse sobre el carácter oneroso de las actividades deportivas ejercidas profesionalmente ${ }^{28}$, la navegación marítima y aérea, etc. Llegando finalmente a determinar que "el sistema general del Tratado implica que todos los sectores de la vida económica están comprendidos en el conjunto de las disposiciones del Tratado, salvo que éste prevea expresamente su excepción" ${ }^{29}$-como ocurre, por ejemplo, con los empleos en la Administración Pública previstos en el art. 39.4 TCE, anterior art. $48.4 \mathrm{TCEE}^{30}$. Por otro lado, la realidad y efectividad de la actividad se aprecia

22.- Asunto 53/81, op. cit., pág. 1052.

23 - Asunto 75/63, op. cit.

24.- Asunto 27/91, Sentencia de 21 de noviembre de 1991, Rep. 1991-I, pág. 5531 y ss.

25 .- Asunto 53/81, op. cit.

26.- Asunto 197/86, Sentencia de 21 de junio de 1988, Rep. 1988, pág. 3025 y ss.

27.- Asunto Bettray o Asunto 344/97, Sentencia de 31 de mayo de 1989, Rep. 1989, pág. 1621 y ss.

28.- Asunto 36/74, Sentencia de 12 de diciembre de 1974, Rep. 1974, pág. 1404 y ss.

${ }^{29}$.- Asunto 167/73, Sentencia de 4 de abril de 1974, Rep. 1974, pág. 359 y ss.

30.- Por estos ha de entenderse aquellos que supongan "una participación directa o indirecta, en el ejercicio del poder público o en las funciones que tiene por objeto la salvaguardia de los intereses generales del Estado o de las demás colectividades" no encontrándose incluidos aquellos empleos que "aun teniendo un vínculo jurídico con el Estado o con otros organismos de Derecho público, no implican ninguna participación en las tareas propias de la Administración Pública propiamente dicha". Vid. Asunto 148/79, Sentencia de 17 de diciemgbre de 1980, Rep. 1980, pág. 3881 y ss.; Asunto 173/94, Sentencia de 2 de julio de 1996, Rep. 1996-I, pág. 3265 y ss.; Asunto 290/94, Sentencia de 2 de julio de 1996, Rep. 1996-I, pág. 3285 y ss.; y Asunto 473/93, Sentencia de 2 de julio de 1996, Rep. 1996-I, pág. 3207 y ss.; 
independientemente de la regularidad o de la importancia de la misma, lo que significa que " $n i$ la productividad más o menos alta ni la fuente de recursos que permiten la retribución pueden tener en ningún tipo de consecuencias respecto al reconocimiento o no de una persona como trabajadora'31. Ello supone que el trabajo a tiempo parcial no está excluido de la libre circulación y que a priori tampoco pueden excluirse aquellas actividades que sean ocasionales o intermitentes, tal y como confirman los pronunciamientos LannieBlum, ${ }^{32} \operatorname{Kempf}^{33} \mathrm{O}$ Bromm $^{34}$.

En suma, todo esta jurisprudencia sobre la necesidad de que la actividad sea económica, real y efectiva ha conducido a que, a efectos de la libre circulación de trabajadores, sea indiferente la naturaleza del vínculo jurídico que une a las partes de una relación de trabajo, por lo que la noción de actividad asalariada en el sentido del Derecho Comunitario puede perfectamente englobar una relación de trabajo de Derecho público en el sentido del Derecho nacional siempre que no comporte una participación directa o indirecta en el ejercicio del poder público; o incluso puede abarcar un periodo en formación necesario para lograr una determinada profesión ${ }^{35}$.

Que la prestación sea onerosa es otro de los elementos objetivos que el TJCE exige para estar en presencia de una relación de trabajo a la que se le pueda aplicar la libertad de circulación. Dicho de otro modo, es necesario que el sujeto que presta la actividad económica, real y efectiva a favor de otro sujeto reciba a cambio una remuneración. Este requisito excluye cualquier actividad desinteresada de la noción de actividad asalariada comunitaria. Sin embargo, también hay que tener en cuenta que no existe ningún pronunciamiento en el que se prevea que la remuneración deba alcanzar una cifra determinada, ni el origen de las fuentes que pueden servir para su financiación (que incluso puede provenir del erario público) $)^{36} \mathrm{o}$ la forma de remuneración de que se trate (si es a la par, por pieza, etc.... $)^{37}$

Otro elemento nuclear que objetivamente sirve para calificar como relación de trabajo a una actividad onerosa, real y efectiva es que ésta se preste a favor de otra persona. Por consiguiente es necesario que la actividad económica ejercida lo sea en provecho de quien la paga, y bajo su dirección. Esto significa que el carácter económico de la actividad no guarda relación con que quien la realiza obtenga una remuneración, ya que una cosa es que el trabajador perciba una contraprestación por su trabajo y otra distinta es que el beneficiario de ese trabajo obtenga un rendimiento económico del mismo. Pues como ha señalado el TJCE aunque aparentemente concurran los requisitos objetivos de la actividad asalariada si carece de naturaleza económica (como ocurre por ejemplo con las actividades de inserción profesional) no puede ser considerada como tal.

Como puede observarse la intervención frecuente del TJCE en esta materia no sólo ha permitido en un sinfín de ocasiones interpretar o corregir la normativa comunitaria sino que al mismo tiempo evidencia los problemas que se derivan de la falta de una sistematización jurídica de la relación

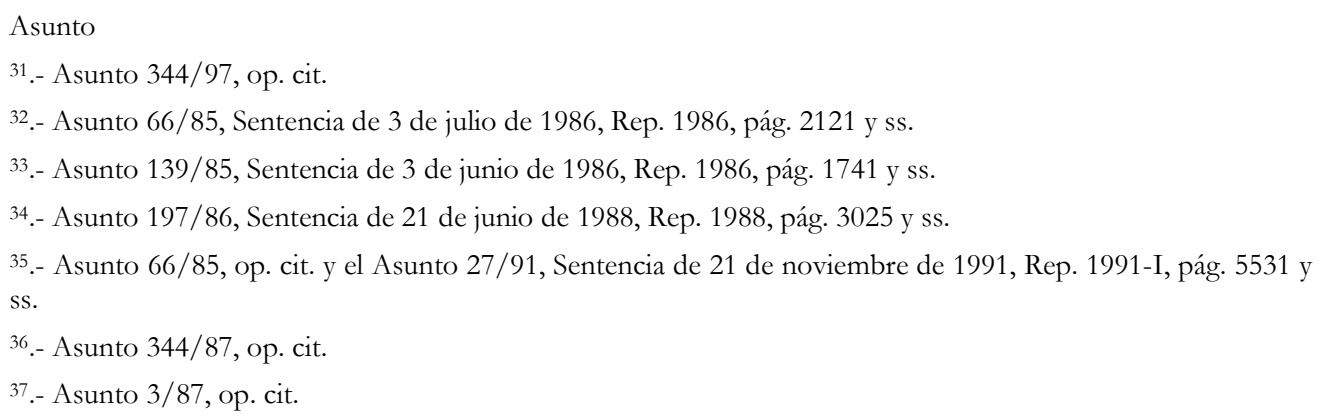


REJ - Revista de Estudios de la Justicia - No 5 - Año 2004

de trabajo. Esta actuación cuasi-legislativa no ha de suplir ni suple en absoluto la necesaria actuación legislativa, dado que la sistematización jurídica de la relación de trabajo y de las nociones que la misma encierra ayudarían por un lado, a la correcta aplicación de la normativa comunitaria, y por otro, asegurarían su eficacia. Pues como ha sostenido el Tribunal existe, un vínculo estrecho entre la existencia o inexistencia de una definición comunitaria de la relación de trabajo asalariada, por un lado, y por otro, la efectividad o inefectividad del Derecho Social Comunitario; y que, además tiene un alcance más extenso que la libre circulación, por lo que puede ser transpuesta a otras cuestiones. La experiencia de la jurisprudencia comunitaria en relación con la libre circulación de trabajadores debe servir para mostrar hasta que punto una sistematización jurídica de la relación de trabajo puede resultar útil para la propia evolución del Derecho Comunitario.

Una vez concluido que sería deseable y necesario establecer una noción legal de trabajador a nivel comunitario el siguiente paso es interrogarse sobre cómo actuar para alcanzar su establecimiento. Es fuerte la tentación de proponer una solución que apueste por una evolución hacia una definición unificada del contrato de trabajo. Esta apuesta, sin duda, condenaría a desparecer, a corto plazo, a todas aquellas calificaciones jurídicas fundamentadas en la consideración del trabajo a través del método casuístico. Y no puede desconocerse que éstas aportan un dato importante como es que la evolución de la relación de trabajo ni es simple ni es tan fácilmente gobernable. Y ello porque, pese a que sea cierto que en los países europeos se perciben signos claros de un progreso hacia la tendencia a la unificación de la relación de trabajo asalariado. Lo cierto es que, en realidad, esta tendencia es más aparente que real. En el sentido de que la unificación se produce, por un lado, porque ciertas categorías de trabajadores que hasta el momento estaban excluidos del juego del Derecho del Trabajo son ahora sometidos a éste pero a través de estatutos especiales o aplicándoles un cierto "derecho común del trabajo"; y por otro, porque dentro de la categoría del trabajo asalariado regulado desaparecen antiguas divisiones entre categorías que ayudan a relativizar aún más la noción de la relación de trabajo asalariada $^{38}$. Estas transformaciones conducen a la emergencia de una regulación del trabajo de segundo tipo en la que la mayor parte de las nociones nucleares del Derecho del Trabajo se encuentran difuminadas o ausentes. A esta dualidad de regímenes jurídicos corresponde una explosión de colectividades de trabajo ${ }^{39}$ en la que coexisten trabajadores supraprotegidos con trabajadores del segundo mercado de trabajo que se encuentran colocados en un universo jurídico en el que la regla es la precariedad económica ${ }^{40}$.

A los efectos que aquí interesan esta evolución supone una alteración en la capacidad integradora del Derecho del Trabajo, que deja de definir una identidad jurídica común a todos los trabajadores porque cada uno de ellos es reenviado a una situación jurídica particular, variable según la rama profesional, la empresa o el tipo de contrato que tenga.

Ante esta doble tendencia a la generalización y diversificación de la tutela, ¿qué papel juega o debe jugar el Derecho Comunitario? Al nivel comunitario se le abren dos posibilidades: o fijar una noción igual para todos los Estados, o por el contrario, la reenvía a los Estados para que sen ellos los que la adapten en función de las particularidades de su respectivo ordenamiento jurídico. Ambas posibilidades tienen ventajas pero también cuentan con algunos inconvenientes.

\footnotetext{
38.- Al respecto puede consultarse para una visión en Europa: AA.VV., Flexibilidad de trabajo en Europa (R.Boyer), Madrid (MTSS), 1986.

39.- MAILLARD, J., L'éclatement de la colectivité de travail: observations sur le phénomène d'extériorisation de l'emploi, DS, 1979, pág. 323 y ss.

40.- ROJO TORRECILLA, E., Desarrollo social y económico para luchar contra la exclusión, La Factoría, no 1, 1996.
} 
Una definición de corte universalista con validez general puede, en ocasiones, revelarse no suficientemente elástica para atender a la diversidad de nuevas formas de trabajo que el sistema productivo genera; al tiempo que también puede ser un obstáculo para seguir los diferentes itinerarios de que se compone la vida profesional de un trabajador. Pues hoy, más que nunca, es dificil encontrar que quien trabaja para otro lo haga a lo largo de su vida profesional bajo la misma forma. Además, una apuesta en tal sentido puede suponer desconocer las tendencias actuales de los ordenamientos jurídico-laborales de la mayoría de los Estados Miembros que, apuestan por una flexibilización de las tutelas como mecanismo para hacer frente a las importantes tasas de desempleo.

Por otro lado, si se apuesta por la segunda opción, es decir, por el que la delimitación de la noción de trabajador sea reenviada a los Estados Miembros para que procedan a su adaptación en función de las peculiaridades derivadas de su respectiva tradición jurídica, esta solución cuenta con el inconveniente de colisionar con algunos de los principios que inspiran el Derecho Comunitario, además de conllevar problemas de tipo técnico que dificultan su aplicación práctica. Por ejemplo, uno de los principios que inspiran la Comunidad Europea es el "acercamiento de las condiciones de vida y trabajo de los trabajadores de la Comunidad Europea" (art. 7 TCEE), por lo que dificilmente se podrá ver cumplido este objetivo si desde la instancia comunitaria se pretende consolidar jurídicamente las diferencias derivadas de la diversidad de regulaciones que sobre las formas de empleo existen en los Estados Miembros.

Por otro lado, las consecuencias que se derivan de la aplicación del principio de subsidiariedad permiten llegar a la misma conclusión, esto es, la dificultad de establecer una noción armonizada de trabajador. En la medida en que conforme a este principio la instancia más cercana al ciudadano estaría llamada a intervenir de entre las instancias implicadas, su aplicación en la determinación de la noción de trabajador comporta que cada Estado miembro resulta competente sin que su respectiva noción pueda ser impuesta en el territorio de otro Estado Miembro. De este peculiar sistema de distribución competencial se deriva también que la Comunidad no mantenga ningún marco competencial con el que pueda intervenir.

De ahí que por aplicación estricta de este principio una intervención comunitaria tampoco sería posible. Sin embargo, pese a los inconvenientes señalados con respecto al establecimiento de una noción de trabajador a nivel comunitario, lo cierto es que la experiencia que arroja la aplicación de la libertad de circulación demuestra que es necesario la adopción de definiciones comunes que delimiten con claridad los conceptos jurídicos utilizados para que la norma comunitaria sea efectiva. Sin que ello sea obstáculo para que los Estados puedan acabar precisando y adaptando dichas definiciones a sus peculiaridades o que los jueces puedan resolver las cuestiones que se susciten como resultado de su aplicación.

La jurisprudencia en aplicación de la libertad de circulación también refleja otra serie de consideraciones igualmente válidas para diseñar un método de aproximación a la sistematización de la relación de trabajo. Por un lado, es necesaria una definición comunitaria de las nociones jurídicas que emplea el Derecho europeo, desde el momento en que éstas delimitan su campo de aplicación, es decir, sólo por expresa previsión de la norma europea puede remitirse una definición a los derechos nacionales y el silencio de los textos sobre este punto autoriza al juez europeo a definir las nociones que emplea. Por otro lado, las nociones de las que dependen los derechos y libertades fundamentales deben recibir una interpretación extensiva. Y finalmente, la sistematización jurídica de la relación de trabajo no requiere forzosamente una única definición, en la medida que ésta debe adecuarse a la finalidad perseguida por cada norma, que no siempre coincide. En conclusión, puede decirse que 
cualquier intento de sistematización de la relación de trabajo debería ser, si se tiene en cuenta la experiencia que arroja la libre circulación de trabajadores comunitaria, diversificada y funcional. ${ }^{41}$

Naturalmente, que la noción de trabajador a nivel comunitario no tenga que ser única y pueda ser funcional y diversificada encuentra su límite en que no se empleen nociones tan genéricas de trabajador que por imprecisas resulten impracticables y acaben por desnaturalizar la noción misma de trabajador en el plano comunitario. Es preciso emplear una noción que la haga reconocible. Como se ha visto, este riesgo no se produce a nivel interno de los Estados pues la mayoría de ellos cuentan con referencias más o menos explícitas a la noción de trabajador.

Sin embargo, también puede ser un riesgo caer en el otro extremo, es decir, intentar proporcionar una noción lo más precisa posible sobre quien y bajo qué circunstancias va a ser considerado trabajador. En este caso, el inconveniente reside en que el mundo del trabajo es una parcela de la actividad humana que en los últimos tiempos se está transformando con suma rapidez, por lo que si este escenario cambia es previsible que quienes son sus principales protagonistas, el trabajador y el empresario, también se vean afectados por dichas transformaciones. Bajo esta perspectiva, si la realidad sobre la que se proyecta la norma se altera, lo deseable es que la norma sea lo suficientemente flexible para que sea capaz de seguirla, pues en caso contrario la norma puede perder la finalidad por la que fue aprobada. Es necesario encontrar una definición lo suficientemente amplia que sin ser vaga permita edificar el conjunto de derechos sociales que se asocian a la persona del trabajador, y que al mismo tiempo se componga de una serie de notas que proyectadas en el tiempo no supongan que la noción se convierta en obsoleta por inaplicable.

La posible sistematización de la relación de trabajo a nivel comunitario nos sitúa necesariamente una vez más ante la oposición que comportan las dos tradiciones de la cultura jurídica europea. Sin bien la cuestión no radica tanto en escoger una u otra concepción sino en si es posible asegurar su compatibilidad en unas condiciones en que toma relieve la experiencia adquirida en derecho positivo. Dicho de otro modo, se trataría de contemplar al mismo tiempo la unidad y la pluralidad, la dimensión contractual y estatutaria de la relación de trabajo.

En un contexto como el actual, en el que la tutela que proporciona el contrato se está diversificando y en el que pierde nitidez la relación de trabajo asalariada en el Derecho de los países miembros, debe aparcarse la elección en bloque del método casuístico o el método sistemático. Pues una de las aportaciones claves del Derecho Comunitario en este punto ha sido el demostrar que la noción de trabajador no es reconducible exclusivamente a aquella de parte del contrato, pues como se ha visto desde la óptica de las exigencias de la protección social o de la libre circulación el trabajador no pierde tal condición incluso en períodos en los que no está vinculado a un contrato de trabajo: cuando busca un empleo, cuando está disfrutando de período de formación o de reconversión profesional, o cuando goza de un años sabático, etc.

En su lugar, los esfuerzos deben dirigirse entonces hacia una noción que asegure al mismo tiempo la unidad y la diversidad constituyendo así una fórmula flexible, adaptable a los cambios sociales en curso, y ello al margen de que dicha noción tenga que ajustarse a las funciones de articulación de la autonomía de la voluntad y determinación del campo de aplicación de las normas del trabajo que le correspondan.

Igualmente esta noción debe comprender los distintos criterios objetivos de la relación de

41.- Asunto 85/96, op. cit., pág. 2691 y ss, apartado 31. 
trabajo asalariado, tal y como éstos se desprenden de los Derechos nacionales y del Derecho comunitario, es decir, la existencia de una prestación de trabajo ejecutada a cambio de una remuneración y en situación de dependencia de un empleador. De lo contrario la noción puede resultará tan amplia y vaga que devenga inaplicable.

La exigencia de una remuneración no implica mayores precisiones dado que como se ha visto la jurisprudencia derivada del TJCE descarta todo umbral mínimo de salario en este campo, por lo que es suficiente que exista. En cambio, cómo formular los dos restantes criterios objetivos que caracterizan el contrato de trabajo -la prestación de trabajo y la dependencia- deviene una cuestión delicada por la propia diversificación de las formas de empleo y las necesidades de regulación correspondientes en cada Estado Miembro.

Lo cierto es que ha pasado a ser verdaderamente imposible encerrar esta diversidad en una única fórmula. El análisis comparativo de los países comunitarios revela la existencia de tres posibles métodos para hacer frente a esta dificultad. De un lado, el método del haz de indicios que a grandes rasgos consistiría en el que juez proceda a una evaluación conjunta de la relación de trabajo que debe calificar y busque si existe un número suficiente de indicios de una relación de poder. La base de esta técnica sería que ninguno de los indicios puede por si sólo ser determinante. Esta técnica es universalmente empleada, pero la lista de indicios utilizados varia de un sistema jurídico a otro (esta técnica se emplea tanto en los sistemas de Common Law, por ejemplo, en Gran Bretaña, como en los sistemas continentales: Francia, Alemania, Bélgica, Países Bajos, Portugal, España, Luxemburgo e Italia) y tiene la ventaja de la soltura y de la adaptabilidad, pero el inconveniente de generar inseguridad jurídica, por cuanto queda al arbitrio exclusivo del juzgador. Por otro lado, la técnica de la asimilación legal suprime esta inseguridad pero es de gran rigidez y tiene el inconveniente de descansar en una base corporativa. Esta técnica se encuentra en ciertos países, y consiste en la asimilación legal de ciertas categorías de trabajadores a los trabajadores asalariados. Tiene una dimensión corporativa manifiesta en la medida en la que descansa sobre la noción de profesión: el punto de partida de esta profesión reposa sobre el vínculo de subordinación que es suficiente para aplicar el estatuto de los asalariados. Otra de sus características es que permite dosificar la aplicación de este estatuto, porque permite modular la asimilación, que puede ser total o parcial. Y, finalmente, el último modo posible de sistematizar la relación de trabajo es acudiendo a la multiplicidad de definiciones, que puede servir para modular el campo de aplicación del Derecho de Trabajo, pero que puede tener el inconveniente de favorecer el individualismo corporativo y la desintegración social si estas definiciones no se constriñen en un marco jurídico suficientemente cohesionado.

Por consiguiente, la única manera posible de poder realizar una aproximación enteramente comunitaria, salvando los inconvenientes que presentan los métodos que emplea cada Estado miembro, es combinándolos, esto es, asimilándolos a la noción empleada en las disposiciones sobre libre circulación e igualdad. Emplear una definición básica de contrato de trabajo mediante la técnica del haz de indicios, estableciendo los factores que no van a tener ningún efecto sobre la calificación del contrato (que según el TJCE pueden ser. el tiempo de trabajo, el lugar de trabajo, la duración del contrato, la naturaleza de las funciones ejercidas, etc.) cada vez que una disposición tenga que definir derechos inherentes a la persona del trabajador y cuando sea preciso vincularla a la noción de contrato de trabajo.

Bajo esta concepción, el sujeto vinculado por una relación de trabajo, expresión que en la terminología comunitaria refleja una voluntad de interpretación más extensiva, sería la persona llamada trabajador dependiente que se compromete a trabajar personalmente a cambio de remuneración en el marco de una organización dirigida por otra persona, llamada empleador. Mientras que la dependencia es definida por remisión al criterio de integración en una organización dirigida por otros, dado que este 
criterio es el que se desprende del análisis comparado de la mayoría de países europeos; el criterio de la integración abriría la puerta a la utilización por el juez de la técnica del haz de indicios, pero con un alcance limitado por la existencia de una lista de indicios que se reputan indiferentes, lista que operaría como un modo de asimilación legal de los contratos cercanos al contrato de trabajo, cualquiera que fuera su calificación por el derecho interno.

Naturalmente, se puede estar más o menos de acuerdo con esta formulación pero quizás lo verdaderamente importante no es, en este momento, ni su precisión ni su corrección técnica sino el mismo hecho de que exista en el ámbito comunitario, ya que sólo así es posible la intervención del TJCE para asegurar su respeto y el conjunto de derechos que se derivan de la misma.

\section{La recomposición de la noción de trabajador a la luz de la evolución del Derecho Comunitario y del Derecho Comparado Europeo: la tutela del trabajo prestado a favor de otro.}

La noción legal de trabajador que se desprende de la mayoría de ordenamientos jurídicos del entorno europeo ha quedado desbordada por la variada realidad social sobre la que pretende incidir. En este sentido, puede afirmarse que se asiste a un fenómeno de adaptación del Derecho del Trabajo a los cambios cíclicos de orden productivo y/u organizativo que son producto del sistema capitalista. Ello tiene como resultado directo, y no como consecuencia patológica como se creyó en otras épocas, la atribución de una naturaleza tuitiva al ordenamiento jurídico-laboral. Siendo precisamente la recuperación de esta función, tradicionalmente asociada al Derecho del Trabajo, la que conviene rescatar para afrontar los desajustes que se producen entre el prototipo normativo actual y la realidad social subyacente. Es decir, de lo que se trata ahora es de seguir protegiendo en función de las necesidades reales de tutela de los sujetos que acuerdan una relación de trabajo; dado que el Derecho el Trabajo debe continuar siendo el instrumento que nivele las desiguales relaciones de poder existentes en el proceso productivo. ${ }^{42}$

El Derecho del Trabajo no puede continuar concibiéndose como un medio para luchar contra las disfuncionalidades derivadas del funcionamiento del mercado, aun cuando pudiera reconocerse que el mercado pudo ser un factor dinamizador, en otros tiempos (en este sentido, las primeras intervenciones de principios del sigho XIX en materia de condiciones de trabajo o el desarrollo comunitario del principio de libertad de circulación de trabajadores). La recuperación de la mejor tradición del Derecho del Trabajo en su función de protección del débil se fundamenta no sólo en razones de tipo histórico (a modo de ejemplo, aquí podrían citarse todas aquellas normativas que encontraban el fundamento de su intervención no en la caracterización de la prestación de trabajo del sujeto sino en su situación económica o en su mayor necesidad de protección, por ejemplo, por su mayor exposición a sufrir accidentes), sino también por el mismo juego de los valores constitucionales que recoge la mejor tradición jurídica europea. ${ }^{43}$

La cuestión no se centra ya exclusivamente en localizar el supuesto de hecho que posibilita la aplicación de la norma laboral, que sigue siendo la figura del contratante débil, sino en la forma de encontrar un criterio unitario que permita su reformulación atendiendo a las transformaciones que

\footnotetext{
42.- PERULLI, A., Il diritto del lavoro tra crisi della subordinazione e rinascita del lavoro autónomo, Dir. Lav., $\mathrm{n}^{\circ}$ 2, 1997, pág. 180 y ss; GIUGNI, G., El desafio de la innovación en el Derecho del Trabajo, RR. LL, 1994 - II, pág. $37^{\circ}$.

43.- CASTEL, R., Droit du travail: redéploiement ou refondation?, DS, $\mathrm{n}^{\circ}$ 5, 1999; DE MUNCK, J., Le trois crises du droit du travail, DS, $\mathrm{n}^{\circ}$ 5, 1999.
} 
sufre hoy en día el mundo del trabajo ${ }^{44}$. Esto es, hay que decidir si el Derecho del Trabajo va a tener una función tutelar abierta a cualquier forma de trabajo o a cualquier sujeto que trabaje con independencia del tipo de vínculo jurídico que una al sujeto a su trabajo; o por el contrario, si va a seguir manteniendo una actitud selectiva, protegiendo sólo a determinados trabajadores. ${ }^{45}$

La primera opción supone proteger a los sujetos en atención a las necesidades de tutela que se derivan del desarrollo de su prestación de trabajo, por lo que este planteamiento implícitamente lleva en sí mismo el reconocimiento de la necesidad de articular un sistema gradual de tutelas. Sistema que abarcaría una serie supuestos a los que se garantizaría la máxima protección por medio de una importante intervención heterónoma en la regulación de la relación de trabajo, hasta colectivos a los que se les aplicaría unas mínimas tutelas ${ }^{46}$. Por el contrario, la óptica del segundo planteamiento consistente en que el Derecho del Trabajo mantenga una actitud selectiva, se orienta principalmente a las condiciones en que el sujeto desarrolla su trabajo y deja en un segundo plano el desarrollo de tutelas en la medida en que se atribuyen en bloque. Bajo esta perspectiva, el Derecho del Trabajo continuaría manteniendo un cuadro binario de protección, esto es, un esquema en el que habría sujetos protegidos y sujetos no protegidos, y en el que sería necesario adoptar un criterio de selección uniforme que permitiera trazar con claridad la línea entre los incluidos y los excluidos.

Sin embargo, la realidad del mundo del trabajo es mucho más variada que la que se puede recoger en un precepto jurídico. Prueba de ello son los abundantísimos pronunciamientos jurisprudenciales que intentan realizar una labor de adecuación de la norma a la realidad. Sin embargo, el hecho que se encargue al juez el clarificar el alcance de la norma en cada momento no es una solución plenamente satisfactoria por dos motivos: de un lado, porque los Tribunales no pueden suplir la función de las normas cuando no se adecuan a la realidad que pretenden regular y, por otro lado, porque en cualquier caso los pronunciamientos jurisprudenciales no pueden ir más allá de las previsiones normativas, con lo que si éstas establecen la aplicación o no de un conjunto normativo en bloque, los jueces no pueden tampoco apartarse en exceso de este esquema. En consecuencia, con esta opción se continúa en el mismo punto de partida, la necesidad de encontrar un criterio sobre el que estructurar las tutelas derivadas de la prestación del trabajo a un ajeno.

Naturalmente, también puede alegarse que si los supuestos de hecho son más variados que los que contempla la norma, este inconveniente puede resolverse manteniendo el prototipo normativo y articulando al mismo tiempo las correspondientes adaptaciones tomándolo como punto de partida y bajo la forma de relaciones especiales de trabajo. Se trataría de atribuir al prototipo normativo, caracterizado si se quiere por varios elementos bien delimitados, la función estructural de primera selección y unificación de tratamientos, y a partir de ahí se irían sucediendo las adaptaciones necesarias al mismo. Esta opción supone admitir la coexistencia de un conjunto de normas uniformes

\footnotetext{
44.- ROMAGNOLI , U., Il lavoro e i lavori, Dir. Lav., nº 3, 1988, pág. 406 y 407.

45.- Algunos aspectos de este debate pueden encontrarse en CABERO IGLESIAS, M., El Derecho del Trabajo para el siglo XXI, DL, $\mathrm{n}^{\circ}$ 53, 1997; DURAN LÓPEZ, F., Globalización y relaciones de trabajo, REDT, $\mathrm{n}^{\circ}$ 92, 1998; PÉREZ DE LOS COBOS, F., Sobre la globalización y el futuro del Derecho del Trabajo, DL, $\mathrm{n}^{\circ}$ 60, 1999; ROMAGNOLI, U., Globalización y Derecho del Trabajo, RDS, nº 5, 1999; ORTIZ LALLANA, M. C., La supervivencia del Derecho del Trabajo, AL, no 42, 1999; RODRÍGUEZ PIÑERO, M., El Derecho del Trabajo a fin de siglo, RR.LL., no 24, 1999; OZAKI, M., Relaciones laborales y globalización, RR.LL, 1999 - I; RODRÍGUEZ PIÑERO, M., Política de globalización y condiciones de trabajo, RR.LL., ${ }^{\circ}{ }^{\circ} 11,2000$.

46.- Pocos son los estudios doctrinales que se han ocupado de aboradar esta cuestión dado que la mayoría de los autores se siguen centrando en la delimitación del núcleo básico de tutela de la relación de trabajo. Sin embargo, unas primeras reflexiones sobre la cuestión pueden encontrarse en SUPIOT, A., Les nouveaux visages de la subordination, DS, $\mathrm{n}^{\circ}$ 5, 2000.
} 
y otro de reglas especiales y o diversificadas y establecer si en la determinación de las reglas especiales es necesaria la intervención del legislador o, por el contrario, son las partes las que libremente deben ponerse de acuerdo. Lo que en cualquier caso, lleva de nuevo al mismo punto de partida, esto es la previa delimitación del criterio que permitirá el tratamiento unificado de las tutelas ${ }^{47}$.

Sin embargo, un planteamiento de este tipo presenta todavía el inconveniente de que no resuelve en absoluto las necesidades de tutela de aquellos trabajos que, pese a situarse en la proximidad del prototipo normativo de referencia, no cuentan con protección alguna (zonas grises); o la de aquellos otros que, habiendo sido expresamente excluidos por el prototipo normativo, dan indicios de requerir en realidad idénticas necesidades de tutela como, por ejemplo, sucede con ciertas manifestaciones de trabajo autónomo. Ambos supuestos conforman hoy en día situaciones fácilmente detectables en la realidad social de las que el ordenamiento jurídico laboral no puede por más tiempo desentenderse, en atención a su función secular de protección de la parte débil de la relación de trabajo. Esto es, debe haber una correspondencia entre la condición social del trabajador, su situación de subordinación económica y social y la transposición de dicha condición en un sistema de reglas de tutela del contratante débil en el marco del ordenamiento laboral.

Examinadas las distintas opciones y las previsiones normativas de que dispone ya el ordenamiento jurídico, en ese caso, ¿cómo puede promoverse su reacción en vista del desfase que el mantenimiento de un prototipo normativo concebido en los albores del fenómeno industrial con respecto a un tipo social determinado produce frente al desarrollo de nuevas situaciones de hecho que no son susceptibles de ser reconducidas a dicho prototipo pero que también tienen sus mismas necesidades de tutela? En este punto, se abren dos caminos: de un lado recomponer la noción que se desprende del prototipo normativo por medio de su relectura a la luz del Derecho Social Comunitario; o bien, adoptar una perspectiva de Derecho comparado que permita reconstruir la noción a partir de experiencias ya consolidadas.

La primera opción, esto es, la elección del ordenamiento jurídico comunitario como clave de recomposición de la noción actual de trabajador estaría plenamente justificada por la propia naturaleza del Derecho Comunitario. Mientras que la segunda opción también estaría justificada en la medida que el ordenamiento jurídico español, en el pasado y también en la actualidad, se nutre de las tradiciones y experiencias de los ordenamientos jurídicos de los Estados de su entorno. Por tanto, ambos puntos de partida pueden ser válidos, e incluso complementarios, para tratar de realizar la

\footnotetext{
47.- Según resulta del cuadro normativo que se desprende de la noción de trabajador que se contempla en el Estatuto de los Trabajadores, esta parece haber sido la opción por la que se ha apostado en el ordenamiento jurídico español. Hay un tipo central, caracterizado por las notas acumulativas de la voluntariedad, la retribución, la ajenidad y la dependencia, en base al que se articulan un conjunto de relaciones laborales de carácter especial que el mismo legislador se encarga de desarrollar de forma particular en cada caso. Este esquema, aun siendo singular, no resuelve por completo el desbordamiento social actual de la noción de trabajador con respecto a la noción legal dado que ninguno de los ordenamientos jurídicos del entorno español contemplan una figura similar. Es cierto que el listado de relaciones laborales de carácter especial es de naturaleza enunciativa y que puede ser ampliado a nuevas relaciones de trabajo, como contempla el mismo art. 2 ET en su redactado. Pero la solución no pasa por ampliar tanto el listado que lo desnaturalice haciéndolo impracticable. Esto es, cada nuevo trabajo fruto del desarrollo económico o social no puede pretender como respuesta del ordenamiento jurídico una protección de tipo individual o con carácter pormenorizado en función de sus concretas necesidades. Esta solución no sólo sería difícil sino imposible atendiendo a la complejidad del mundo productivo actual y la rapidez con que éste se transforma. No resulta posible cristalizar un fenómeno como el mundo del trabajo, de contornos tan variables, en un precepto jurídico a riesgo de hacerlo tan amplio que se desnaturalice.
} 
Revilla - La relación de trabajo subordinado (...) en el escenario Europeo y Comunitario

operación de reconstrucción que se pretende.

Del tratamiento de la noción de trabajador a nivel comunitario, fruto principalmente del desarrollo del principio de libertad de circulación de trabajadores y de la corta andadura del Derecho Social Comunitario, dado que es un ordenamiento jurídico dinámico que todavía está conformándose, pueden extraerse las siguientes conclusiones, que básicamente giran en torno al hecho de que a nivel comunitario no existe una única noción de trabajador.

La coexistencia de diversas nociones de trabajador en el ámbito comunitario viene justificada de un lado, por la naturaleza misma del Derecho Social Comunitario que, aún siendo un ordenamiento supranacional, se aplica a cada Estado Miembro como parte de su ordenamiento jurídico interno; y de otro, porque el Derecho Social Comunitario debe al mismo tiempo respetar las diferentes tradiciones jurídicas de cada uno de los Estados que componen la Unión Europea. Esto es, la noción de trabajador es concebida desde la instancia comunitaria bajo una perspectiva global suficientemente amplia como para acomodarla a la realidad social de cada país sin quedar desnaturalizada.

Pero quizás la consecuencia más importante que se puede extraer de la coexistencia de diversas nociones de trabajador, al margen de la aludida flexibilidad y adaptabilidad sea la finalidad que persigue y justifica dicha diversidad. Esto es, el empleo de múltiples nociones de trabajador se debe a la voluntad de adaptar la finalidad de la norma a las necesidades del sujeto protegido. De ahí que cada norma pueda contar con un sujeto diferente al que dirigir una protección que se concreta caso por caso, consiguiendo que la normativa se adapte a las necesidades del sujeto protegido y no a la inversa. En este sentido, la intervención heterónoma es funcional y está estrechamente ligada a las concretas necesidades de los colectivos que se persigue proteger.

Naturalmente, el juego simultáneo de diversas nociones de trabajador, la mayor parte reconducibles, sin embargo, a la noción de sujeto protegido, plantea en ocasiones problemas interpretativos que son corregidos gracias a la importante labor de integración que realiza el TJCE. En otras palabras, se parte del convencimiento de que una noción articulada de trabajador es compleja y requiere de un instrumento que no sólo la dote de significado desde la perspectiva comunitaria sino que al mismo tiempo exponga de manera unificada la finalidad que persigue la normativa comunitaria. El TJCE se erige como el intérprete comunitario de la noción de trabajador que de forma necesaria deben respetar los Estados miembros a la hora de incorporar la normativa comunitaria a sus respectivos ordenamientos internos. De ahí que pueda sostenerse que hoy en día la noción comunitaria influye enormemente y de forma directa en la conformación de la noción legal de trabajador en los Estados miembros.

Desde la perspectiva comunitaria, la noción de trabajador es dinámica; inacabada por cuanto forma parte de un proceso de gestación que no ha concluido todavía; funcional en tanto formulada caso por caso; y en consecuencia diversificada y al mismo tiempo unificada por la interpretación que de ella hace el TJCE.

La perspectiva comparada presenta otras líneas de tendencia igualmente útiles. En este sentido, las diversas propuestas tanto doctrinales como legislativas con que se trabaja muestran cómo la realidad que se pretende regular va en estos momentos por delante de las previsiones que contempla el prototipo normativo; situación ésta que no es nueva ya que fue precisamente la constatación de este hecho lo que dio pie, en su día, a la aparición de las primeras normas sobre condiciones de trabajo y a la superación del contrato civil de arrendamiento de servicios. Por tanto, el desajuste entre el prototipo normativo y la falta de protección jurídica de sujetos que se encuentran en 
condiciones similares a las que el prototipo normativo contempla, renueva el viejo debate de las fronteras de protección que proporciona el ordenamiento jurídico en torno a la figura del contratante débil. Y asimismo se vuelve a cuestionar la eficacia misma del prototipo normativo, que se ve afectado en sus mismos fundamentos. Se asume que el criterio que debe adoptarse en la reformulación de la noción legal de trabajador que se emplea ha de estar en directa correspondencia con la función que desde sus orígenes ha desempeñado el ordenamiento jurídico laboral.

Estando claro el criterio que permite articular el conjunto de tutelas, sin embargo, se difiere en la manera de plasmarlo jurídicamente en un tipo normativo, ya que la experiencia muestra que la cristalización de las necesidades de tutela en un esquema en blanco y negro el tipo no puede ser cerrado, porque siempre hay matices que no quedarían suficientemente recogidos y porque constantemente este esquema requiere reajustes. En este sentido se han barajado distintas propuestas: desde las que apuestan por el establecimiento de un continuo de tutelas, sin posibilidad de que existan colectivos que trabajen desprovistos de tutela, hasta llegar al supuesto de protección máxima que sería el coincidente con el trabajador que celebre un contrato de trabajo; hasta los que proponen mantener el sistema tradicional de los excluidos e incluidos, recomponiendo el criterio que permite tal diferenciación pero incorporando una categoría intermedia, que contemple una serie de garantías en función de las necesidades de los sujetos situados en aquella zona próxima a los incluidos. ${ }^{48}$

Estas opciones opuestas, que naturalmente cuentan también con posiciones intermedias más matizadas, tienen importancia en dos sentidos: por un lado, porque rompen con el pensamiento en blanco o negro que supone mantener exclusivamente un único prototipo normativo y, por otro lado, porque conectan claramente el prototipo normativo con la función que desempeña en la articulación de tutelas del ordenamiento laboral. Dicho de otro modo, los dos planteamientos conectan la noción de trabajador con la noción de sujeto protegido, al proporcionar el primero un conjunto de tutelas, un status, que permite entender que se está ante un verdadero sujeto protegido.

Pueden, por tanto, extraerse dos ideas clave del debate que se ha suscitado en el Derecho comparado: por un lado, que el criterio de protección en una relación de trabajo ha de seguir siendo la tutela de la parte débil, esto es, proteger a quien lo necesita y en función de lo que necesita; y en segundo lugar, conservar el prototipo normativo, por cuanto su conformación ha sido el resultado de arduas conquistas sociales a lo largo de muchos años, pero proceder al mismo tiempo a replantearlo en la medida en que las evoluciones a las que asiste el ordenamiento jurídico hoy en día lo están socavando en sus mismos cimientos.

Pese a que sea cierto que las transformaciones que sufre la realidad social sobre la que se estructura el ordenamiento jurídico laboral son tan importantes que cuestionan sus mismos fundamentos, la apuesta que se defiende no precisa de nuevos instrumentos o nuevas construcciones (contrato de actividad, contrato coordinado, etc.). Para avanzar no es preciso acabar con lo conocido, sino que aprovechando lo conquistado es necesario reformular los instrumentos de que ya dispone el ordenamiento jurídico, adecuándolos a las nuevas necesidades de protección. En este sentido, se propugna un redescubrimiento del "trabajo" en sí mismo, dotándolo de un sentido más amplio del que actualmente tiene para desvincularlo del término "empleo". 49

\footnotetext{
48.- Para una visión global d estas propuestas vid. GHEZZI, G., Introdurione generale alle otto proposte di lege, en AA.VV., La disciplina del mercato del lavoro. Proposte per un Testo Unico, Roma (Edesse), 1996, pag. 67 yss.

49.- En la misma línea que se sostiene en AA.VV., Au delà de l'emploi du travail et devenir du droit du Travail en Europe (Rapport pour la Comission Européene), DS , nº 5, 1999.
} 
Revilla - La relación de trabajo subordinado (...) en el escenario Europeo y Comunitario

Con esta nueva visión del trabajo y de la noción de trabajador más material y dinámica se pretenden dos cosas: de un lado, relativizar las diversas formas que el trabajo ha adoptado hasta el momento en el seno de la sociedad capitalista, y así proteger el trabajo como actividad fundamental de la persona en la sociedad actual ${ }^{50}$; y de otro, proporcionar modelos normativos que sigan a la persona en sus diferentes actividades a lo largo de toda su vida. ${ }^{51}$

Naturalmente, que este planteamiento también cuenta con el inconveniente de que previamente se tiene que aclarar el sentido y alcance del "trabajo" (en este sentido, se apuesta por entender como trabajo aquella situación que responda a una obligación o a un vínculo jurídico independientemente de su naturaleza), pero superado este obstáculo, el ordenamiento jurídico protegerá verdaderamente todas las relaciones de trabajo y no exclusivamente una determinada. ${ }^{52}$

Por otro lado, tampoco cabe inferir que proteger todo trabajo signifique una protección indiscriminada en tanto uniforme para todos los casos. Esto es, que el ordenamiento jurídico proteja a todo aquel que trabaje en atención a su condición de sujeto débil de la relación, no significa que dispense la misma protección para todos los trabajadores. Si esto es así, ¿cómo se establece la graduación de tutelas? Es en este punto cuando conviene recuperar de la noción de sujeto débil de la relación de trabajo, ya que se puede articular y justificar en torno a este criterio una intervención heterónoma por parte del ordenamiento jurídico. En otras palabras, al sujeto se le va a proteger en función de las necesidades que tenga, y en este sentido mantener el contrato de trabajo como máxima consagración de esta filosofía resulta vital pero no excluye otras situaciones en las que también pueda haber sujetos necesitados de tutela, dado que hoy en día el prototipo normativo que recoge el ordenamiento jurídico ha dejado de identificarse plenamente con la noción de parte débil de la relación de trabajo.

La noción de trabajador así reformulada, que recuerda en cierto modo al enfoque que se adopta desde el ordenamiento jurídico comunitario, deviene material, en la medida en que comprende realmente todos los sujetos que realizan un trabajo; funcional, porque las tutelas que se derivan de la misma van en función de las necesidades del sujeto que se pretenda proteger: y flexible, porque un planteamiento de este estilo conlleva que el tipo normativo se adapte a la realidad social que pretende regular y no a la inversa, dado que no se fija a priori un único supuesto para el otorgamiento de protección.

Una ventaja de este planteamiento reside en que no se segmenta el ordenamiento jurídico en dos partes estableciendo una frontera entre incluidos y excluidos: toda persona que trabaje está incluida, si bien goza de una protección distinta en atención al grado de necesidad que tenga. Esto permite que el perenne debate sobre las fronteras asociadas a la noción de trabajador, por ser ésta la llave de la protección, quede en un segundo plano; revalorizándose, por el contrario, otro debate mucho más interesante e importante como es el del contenido de la misma protección, y el de la vinculación de la relación de trabajo a la nueva visión de la ciudadanía social ${ }^{53}$.

Como ventaja también puede aportarse que esta visión no está reñida con el mantenimiento

\footnotetext{
50.- GAROFALO, M.G., Un profilo ideologico del Diritto del Lavoro, GDLRI, nº 81, 1999, pág. 29 y ss.

51.- SUPIOT, A., Crítica del Derecho del Trabajo, Madrid (MTSS), Col. Informes y Estudios, 1996, pág. 291 y ss.

52.- ROMAGNOLI, U., Redefinir las relaciones entre trabajo y ciudadania: el pensamiento de Massimo D'Antona, RDS, $\mathrm{n}^{\circ}$ 9, 2000, pág. 15; matizando esta idea: ORTIZ LALLANA, $\mathrm{M}^{\mathrm{a}}$. C $\mathrm{C}^{\mathrm{a}}$., La Transformación del Derecho del Trabajo ante los nuevos retos sociales, Logroños (SPUR), Col. Jurídica, 1999, pág. 36 y ss.

53.- RODRÍGUEZ PIÑERO, M., La nueva dimensión del Derecho del Trabajo, RR.LL, nº 7, 2002, pág. 7.
} 
REJ - Revista de Estudios de la Justicia - No 5 - Año 2004

de la centralidad del contrato de trabajo como instrumento clave de nivelación de desigualdades sociales. Es más, manteniéndolo incluso se clarifica su centralidad al no tratar de incluir en su seno situaciones que realmente no responden a su lógica. Es decir, ya no es necesario forzar el prototipo normativo derivado del contrato de trabajo para poder otorgar protección, porque se entiende que la condición de sujeto débil de la relación de trabajo no puede predicarse exclusivamente de los sujetos que celebren un contrato de trabajo. Ahora bien, también hay que reconocer que la reformulación de la noción de trabajador bajo el prisma de la posición de debilidad en la relación de trabajo cuenta con el inconveniente de que necesita clarificar previamente cuándo se es y cuándo no se es débil. Sin embargo, creo que en este punto conviene tener en cuenta los resultados que hoy en día arroja el hecho de haber pretendido mantener un prototipo normativo lo más preciso y delimitado posible. La realidad cambiante del mundo del trabajo muestra hoy en día poca correspondencia con un prototipo normativo que se forjó hace ya un siglo y este hecho tiene que servir de experiencia para no tratar de precisar excesivamente ciertos conceptos a riesgo de que lo que se defina hoy muy claramente no sirva casi para nada el día de mañana.

Naturalmente, de que no deba existir una única noción de trabajador articulada en torno a un solo prototipo normativo no cabe inferir que no sea necesaria una tarea de delimitación conceptual previa sobre la que poder trabajar, siempre que se entienda que ésta no puede ser definitiva. Por ello, de manera consciente se ha evitado proporcionar en estas páginas una definición de la noción de trabajador en el ordenamiento jurídico ya que su misma formulación supondría repetir algunos errores que se predican precisamente del prototipo normativo actual. En su lugar se ha optado por proporcionar los elementos que hoy en día permiten fraguarse una composición aproximada de la misma y de su posible evolución. 